\title{
Erratum
}

\section{Computational Exploration of the Biological Basis of Black-Scholes Expected Utility Function}

\author{
Sukanto Bhattacharya and Kuldeep Kumar
}

Received 7 April 2007; Accepted 24 April 2007

Copyright () 2007 S. Bhattacharya and K. Kumar. This is an open access article distributed under the Creative Commons Attribution License, which permits unrestricted use, distribution, and reproduction in any medium, provided the original work is properly cited.

Line 5 in the first paragraph of [1] under the section Option basics appeared as follows:

"A call option gives the buyer of the option the right to buy the underlying asset at a fixed price (strike price or $K$ ) at any time prior to the expiration date of the option."

It is commonplace in derivatives literature to denote the strike or exercise price as $K$ (e.g., refer to http://www.duke.edu/ charvey/Classes/ba350/optval/optval.htm). However, in the body of our paper wherever the strike price variable has appeared in a mathematical context it has been denoted as $X$ rather than $K$. So, for sake of maintaining consistency in mathematical notation, we hereby submit to rephrase the above sentence as follows:

"A call option gives the buyer of the option the right to buy the underlying asset at a fixed strike price (or exercise price; generally denoted as either Kor $X$ ) at any time prior to the expiration date of the option."

\section{References}

[1] S. Bhattacharya and K. Kumar, "Computational exploration of the biological basis of blackscholes expected utility function," Journal of Applied Mathematics and Decision Sciences, vol. 2007, no. 1, Article ID 36729, 15 pages, 2007.

Sukanto Bhattacharya: Department of Business Administration, Alaska Pacific University,

Anchorage, AK 99508, USA

Email address: sbhattacharya@alaskapacific.edu

Kuldeep Kumar: School of Business, Bond University, Australia

Email address: kkumar@staff.bond.edu.au 


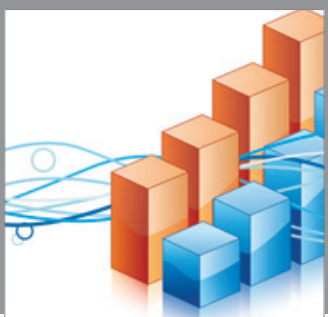

Advances in

Operations Research

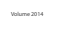

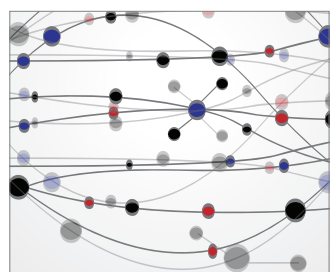

\section{The Scientific} World Journal
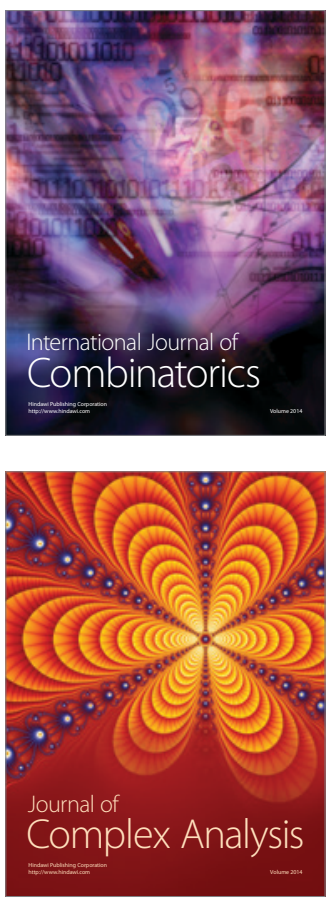

International Journal of

Mathematics and

Mathematical

Sciences
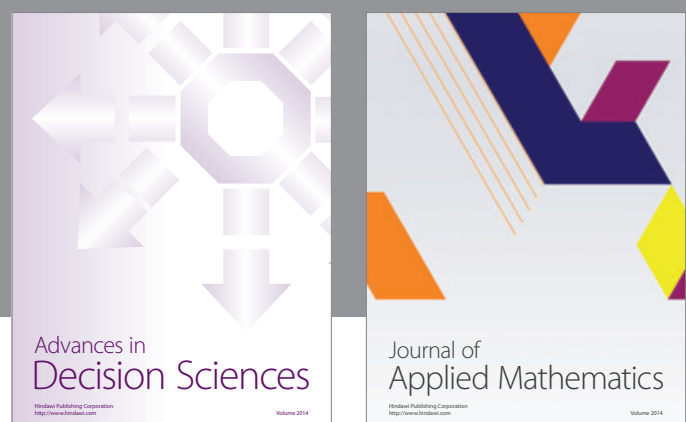

Journal of

Applied Mathematics
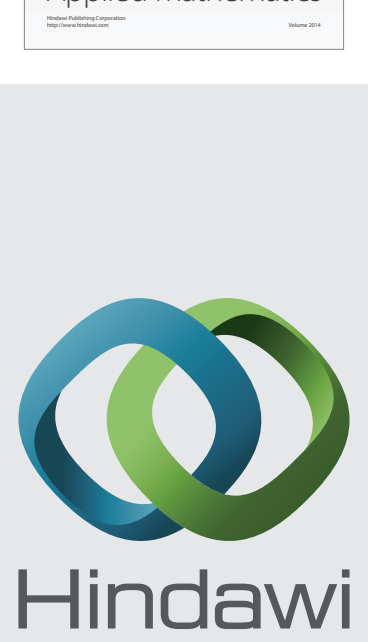

Submit your manuscripts at http://www.hindawi.com
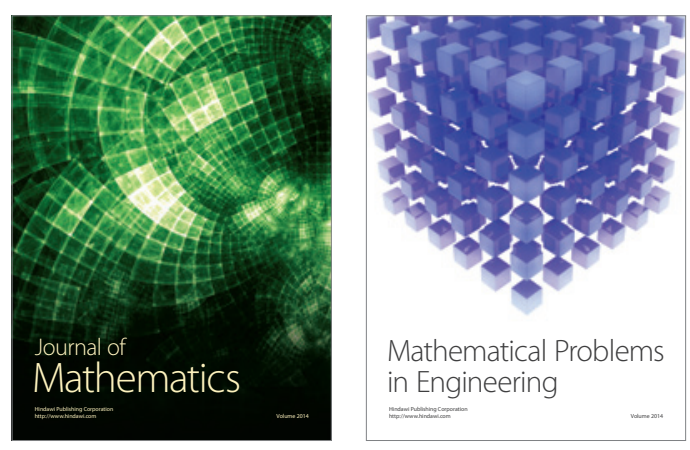

Mathematical Problems in Engineering
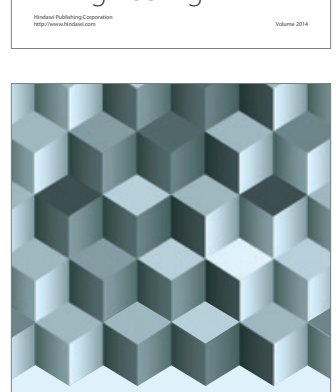

Journal of

Function Spaces
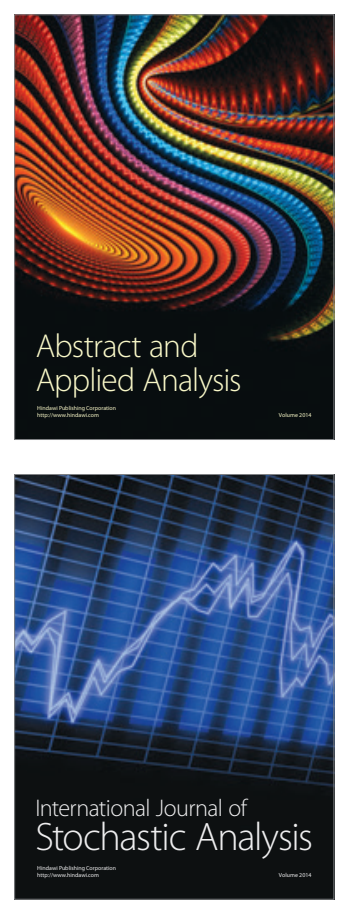

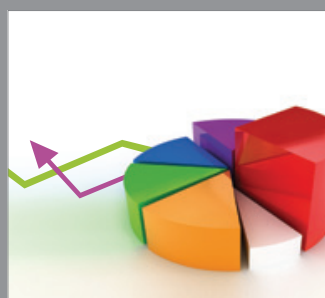

ournal of

Probability and Statistics

Promensencen
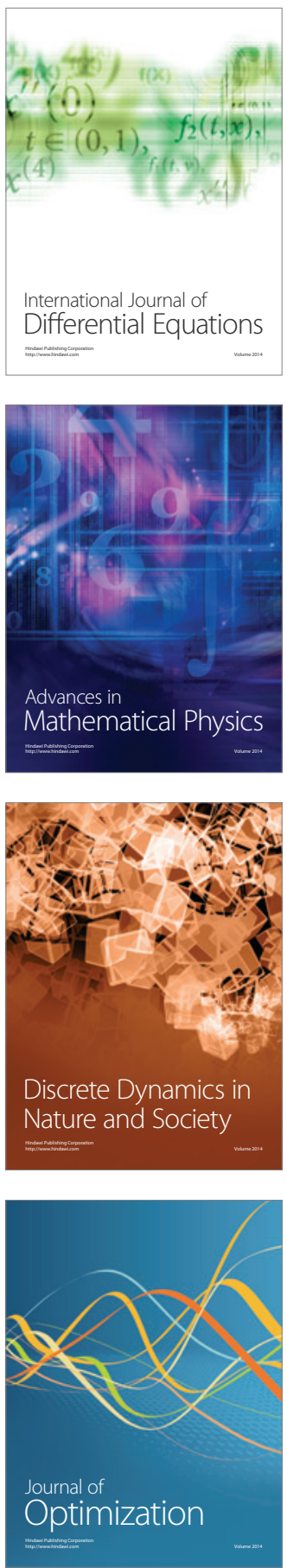